\title{
Radiological Study of Appearance and Fusion of Iliac Crest in hip bone in Bikaner Region in 14-22 Years Age Group
}

\author{
Mathur Indubala', Sajjad Hussain ${ }^{2}$, Bohra Bhavesh ${ }^{3}$, Sharma Yogesh ${ }^{4}$, Agrawal Anjali $^{5}$ \\ ${ }^{1}$ Associate Professor\& HOD, ${ }^{2}$ Assistant Professor, Department of Forensic medicine and Toxicology, PCMS \& \\ RC, Bhopal (MP), ${ }^{3}$ Associate Professor \& HOD, Department of Forensic medicine and Toxicology, Jhalawar \\ Medical College, Jhalawar (Rajasthan), ${ }^{4}$ Professor \& HOD, Department of Forensic Medicine and Toxicology, \\ RNT Medical College and Hospital, Udaipur (Rajasthan), ${ }^{5}$ PG final year, Department of Forensic Medicine and \\ Toxicology, Bhopal (MP)
}

\begin{abstract}
Correct age determination has of great importance in legal prosecution. The principle means, which enable one to form a fairly accurate opinion about age of an individual are general physical development, dentition, secondary sex characters and ossification of bones. Among them Radiological examination of ossification process is most accurate than any other method up to 25 years of age.

This study involves radiological examination of Pelvis (AP view) of 169 individuals for the study of age related appearance and fusion of ossification center of Iliac Crest in the individuals of age group of 14-22 years of both male and female in S P Medical college, Bikaner, Rajasthan.
\end{abstract}

Keywords: Age Estimation, Iliac Crest, X-Rays.

\section{Introduction}

Estimation of reasonably accurate age, plays an important role in civil/criminal cases like personal identification, fixing of criminal responsibility, judicial punishment i.e. in cases of rape, kidnapping, criminal abortion, attempted or evident murder, theft, burglary, dacoity and in various schemes of Social Welfare department i.e. Employment, attainment of majority, marriage contract etc.

Various workers suggest that there is a variation in age estimation, not only in country to country but also in different states of India, so Survey Committee12 (1964) while reporting on medico legal practice in India has recommended to the government to encourage Zone wise study for the problem of determination of age.

\section{Material and Method}

This study is carried out in the Department of Forensic-Medicine and Toxicology in association with radio- diagnosis department of S.P. Medical College and Hospital, Bikaner. The subjects are selected randomly from various schools, from neighborhood of various faculty members and staff as well as cases attending the
OPD of the Forensic-Medicine Department of P.B.M. Hospital, Bikaner. The persons selected for study were grouped as per their stated age, viz.:- 14-15years, 1516 years, $16-17$ years, $17-18$ years, $18-19$ years, $19-20$ years, 20-21 years and 21-22 years. Here age 14-15 years means person of 13 years or more but below 14 years. Age, as stated by them is further confirmed by secondary school certificate, any document reflecting their exact age or entry in their school record.

Selection Criteria for inclusion of person in present study:

C) They should be living in Bikaner region for more than 5 years.

D) They should be free from any physical disability or endocrinal anomaly.

E) Person should have accurate record of their date of birth.

F) Informed expressed verbal consent of the subjects was taken before proceeding to their physical, dental and radiological examination. 
Radiological Criteria for epiphyseal fusion-

The union is taken as complete when the:

a) Diaphyseo-epiphyseal space is completely obliterated and become bony in architecture and density.

b) There is continuity of the periosteum between epiphysis and diaphysis with no notching at the periphery of epiphyseal line.

c) Presence or absence of epiphyseal scar (a white, transverse line) has been disregarded in this connection and considered as recent complete union.

For generalization, fusion in more than $75 \%$ cases is relied upon as complete fusion. Radiological data of appearance and fusion of ossification center of Iliac Crest were reduced to table, of various age groups. Data thus obtained finally, were analyzed and compared with published work of various Indian and foreign workers.

\section{Observation}

In Boys - The appearance of the ossification centre of iliac crest was observed earliest at the age of 14 year, 4 months and 4 days in our study. The appearance of the ossification centre of iliac crest was observed in $90 \%$ of cases in age group $15-16$ years, in $100 \%$ of cases in age group 19-20 years and above. Average age of appearance of iliac crest is 15-16 years in our study. Complete fusion of iliac crest was observed earliest at the age of 16 year, 2 months and 10 days in our study. Complete fusion of iliac crest was observed in $90.91 \%$ of cases in age group of 20-21 years. Average age of fusion of iliac crest was 20-21 years in boys in our study. Age of oldest subject not showing complete fusion of iliac crest was 21 years, 8 months and 19 days in our study.

\section{Appearance and Fusion of the Centre of Iliac Crest in Boys}

\begin{tabular}{|l|l|l|l|l|l|l|l|l|}
\hline \multirow{2}{*}{ S.No. } & \multirow{2}{*}{$\begin{array}{l}\text { Age } \\
(\text { Yrs })\end{array}$} & \multirow{2}{*}{ No. of cases } & \multicolumn{2}{|l|}{ Appearance } & & \multicolumn{2}{l}{ Partial Fusion } & \multicolumn{2}{l}{ Fusion } \\
\cline { 3 - 9 } & & No & $\%$ & No & $\%$ & No & $\%$ \\
\hline 1 & $12-13$ & 12 & - & - & - & - & - & - \\
\hline 2 & $13-14$ & 9 & - & - & - & - & - & - \\
\hline 3 & $14-15$ & 7 & 1 & 14.28 & - & - & - & - \\
\hline 4 & $15-16$ & 10 & 9 & 90 & - & - & - & - \\
\hline 5 & $16-17$ & 17 & 17 & 100 & 3 & 17.65 & 1 & 5.88 \\
\hline 6 & $17-18$ & 25 & 20 & 80 & 2 & 8 & 4 & 16 \\
\hline 7 & $18-19$ & 19 & 18 & 94.73 & 7 & 36.84 & 6 & 31.57 \\
\hline 8 & $19-20$ & 10 & 10 & 100 & 2 & 20 & 6 & 60 \\
\hline 9 & $20-21$ & 11 & 11 & 100 & 1 & 9.09 & 10 & 90.19 \\
\hline 10 & $21-22$ & 12 & 12 & 100 & 1 & 8.33 & 11 & 91.67 \\
\hline
\end{tabular}

In Girls - The appearance of the ossification centre of iliac crest was observed earliest at the age of 15 year, 1 month and 1 day. The appearance of the ossification centre of iliac crest was observed in 100\% of cases in age group 15-16 years and above. Average age of appearance of iliac crest was 15-16 years in girls in our study. Complete fusion of iliac crest was observed earliest at the age of 15 year, 1 month and 1 day in present study. Complete fusion of iliac crest was observed in $100 \%$ of cases in 19-20 years of age group and above in girls. 
Average age of fusion of iliac crest in girls was 19-20 years in our study. Age of oldest subject not showing complete fusion of iliac crest was 18 years, 5 months and 10 days in present study.

Appearance and Fusion of the Centre of Iliac Crest in Girls

\begin{tabular}{|c|c|c|c|c|c|c|c|c|}
\hline \multirow{2}{*}{ S.No. } & \multirow{2}{*}{$\begin{array}{l}\text { Age } \\
\text { (Yrs) }\end{array}$} & \multirow{2}{*}{ No. of cases } & \multicolumn{2}{|c|}{ Appearance } & \multicolumn{2}{|c|}{ Partial Fusion } & \multicolumn{2}{|c|}{ Fusion } \\
\hline & & & No & $\%$ & No & $\%$ & No & $\%$ \\
\hline 1 & $12-13$ & 8 & - & - & - & - & - & - \\
\hline 2 & $13-14$ & 2 & - & - & - & - & - & - \\
\hline 3 & $14-15$ & 2 & - & - & - & - & - & - \\
\hline 4 & $15-16$ & 4 & 4 & 100 & - & - & 3 & 75 \\
\hline 5 & $16-17$ & 6 & 6 & 100 & 2 & 33.33 & 3 & 50 \\
\hline 6 & $17-18$ & 19 & 19 & 100 & 11 & 57.89 & 4 & 21.05 \\
\hline 7 & $18-19$ & 10 & 10 & 100 & 7 & 70 & 1 & 10 \\
\hline 8 & $19-20$ & 5 & 5 & 100 & - & - & 5 & 100 \\
\hline 9 & $20-21$ & 4 & 4 & 100 & - & - & 4 & 100 \\
\hline 10 & $21-22$ & 8 & 8 & 100 & - & - & 8 & 100 \\
\hline
\end{tabular}

\section{Discussion}

In Female: In our study we observed the average age of appearance of ossification centre of iliac crest in female at 15-16 years of age, which is consistent with the observation of the study of Nagi Abdul Wahab Abdulla1 et al (Yemen), Alok Kumar4 et al (Kanpur) and Yatiraj Singi $1^{15}$.

In our study we observed the average age of fusion of the ossification centre of iliac crest in females at 1920 years, which is consistent with the observation of the study of Nagi Abdul Wahab Abdulla1 et al (Yemen) also with observation of Chandresh Tailor ${ }^{13}$ (Surat) and as stated by RK Sharma10, Nagesh Kumar Rao8, Krishan Vij14 and VV Pillay ${ }^{7}$ in their textbooks .

In Male: In our study we observed the average age of appearance of ossification centre of iliac crest in male at 15-16 years of age. The finding in our study is consistent with the observation of the study of Alok Kumar4 et al
(Kanpur) and Apurba Nandy6 they observed that it is 16 years of age and also consistent with Grant's Anatomy2, a standard textbook of anatomy, who stated that it is 16 years of age.

In our study we found the average age of fusion of the ossification centre of iliac crest in males is 20-21 years, which is consistent with the observation of the study of Pardeep Singh, RK Gorea11 who conducted study at Patiala, Punjab and also as stated by N.Reddy 9 in his textbook, that it is $20-21$ years of age also is consistent with the observation of Memchoubi Ph.5 who observed that it is 20 years of age and it is also consistent with the age as stated by PC Dikshit3 in his textbooks.

\section{Conclusion}

Average age of appearance of the ossification centre of iliac crest observed at 15-16 years in boys in our study in Bikaner region. 
Average age of fusion of iliac crest observed at 2021 years in boys in our study in Bikaner region.

Average age of appearance of the ossification centre of iliac crest observed at 15-16 years in girls in our study in Bikaner region.

Average age of fusion of iliac crest in girls observed at 19-20 years in our study in Bikaner region.

Findings of our study are again giving the strength to the workers and Survey Committee 12 report, as they suggest to the government to encourage Zone wise study for the problem of determination of age. This study is an attempt which may be a valuable aid to a forensic practitioner to give the approximate age certificate in medicolegal cases.

Ethical Clearance- Taken from Ethical committee of S.P. Medical College and Group of Hospitals, Bikaner Rajasthan.

\section{Source of Funding- Self}

\section{Conflict of Interest - Nil}

\section{References}

1. Abdulla NAW, Bhasharaheel ABS. Age Estimation by using Pelvic Radiography in Yemen Population. Journal of Islamic Countries Organization for Forensic Medicine 2008; 23-8.

2. Basmajian JV. Grant's Method of Anatomy. 10th Ed: Publisher Williams \& Wilkins; 1980. 314.

3. Dixit PC. Textbook of Forensic Medicine and Toxicology, 3rd ed: PEEPEE Publishers and Distributors (P) Ltd. 2010; 56-57.

4. Kumar Alok et al. Estimation of age from Pelvis A Radiological study. IIJFMT 2004; 1(3): 1-7.

5. Memchoubi Ph. Age Determination of Manipuri Girls from the Radiological Study of Epiphyseal
Union Around the Elbow, Knee, wrist joints and Pelvis JIAFM. 2006; 28(2): 63-64.

6. Nandy Apurba. Principles of Forensic Medicine Including Toxicology. 3rd ed: New Central Book Agency (Pvt) Ltd. London; 2010. 119-127.

7. Pillay VV. Textbook of Forensic Medicine and Toxicology. 16th ed: Paras Medical Publisher; 2011. 66-7.

8. RAO NageshKumar G. Textbook of Forensic Medicine and Toxicology. Jaypee Brothers Medical Publisher (P) LTD. New Delhi; 2000. 19.

9. Reddy KS Narayan. The Essentials of Forensic Medicine and Toxicology. 30th ed: K Sugana Devi Hyderabad; 2011. 59-69.

10. Sharma RK. Concise Textbook of Forensic Medicine and Toxicology. 1st ed: ELSEVIER (A division of Reed Elsevier India Pvt. Ltd.); 2005.

11. Singh Pardeep, Gorea RK, Oberoi SS, Kapila AK. Estimation of Age from Epiphyseal Fusion in Iliac Crest. J Indian Acad Forensic Med. Jan.-Mar. 2011; 33(1): 24-6.

12. Survey committee. Survey committee report on Medicolegal practice in India, Ministry of health 1964; 63.

13. Tailor Chandresh, Govekar Ganesh, Patel Gaurang, Silajiya Dharmesh. Age in Cases of Victims of Sexual Offence. J Indian Acad Forensic Med; 32(4): 303-7.

14. Vij Krishan. Textbook of Forensic Medicine and Toxicology Principal and Practice. 2nd ed: B L Churchill livingstone Pvt. Ltd. New Delhi; 2002. 74-81

15. Yatiraj Singi, Deshmukh Kiran, Bijapur Nagaraj. Assessment of age in adolescents by Radiological examination of pelvis \& hipjoint. International journal of Medical and Health Sciences, April 2012; 1(2): 10-16. 